Review

\title{
Vascular Resection in Perihilar Cholangiocarcinoma
}

\author{
Alejandro Serrablo ${ }^{1,2, * \mathbb{D}}$, Leyre Serrablo ${ }^{3}$, Ruslan Alikhanov ${ }^{4}$ and Luis Tejedor ${ }^{5}$ \\ 1 Section of Surgery, European Union of Medical Specialists, 1040 Brussels, Belgium \\ 2 HPB Surgical Division, Miguel Servet University Hospital, Zaragoza University, 50009 Zaragoza, Spain \\ 3 Medicine School, Zaragoza University, 50009 Zaragoza, Spain; leyre.sc22@gmail.com \\ 4 Division of Liver and Pancreatic Surgery, Moscow Clinical Research Center, 111123 Moscow, Russia; \\ r.alikhanov@mknc.ru \\ 5 Department of Surgery, Punta Europa Hospital, 11207 Algeciras, Spain; tejedor@concadiz.es \\ * Correspondence: aserrablo@salud.aragon.es
}

check for

updates

Citation: Serrablo, A.; Serrablo, L.; Alikhanov, R.; Tejedor, L. Vascular Resection in Perihilar

Cholangiocarcinoma. Cancers 2021,

13, 5278. https://doi.org/10.3390/

cancers 13215278

Academic Editor: Luca Di Tommaso

Received: 3 September 2021

Accepted: 18 October 2021

Published: 21 October 2021

Publisher's Note: MDPI stays neutral with regard to jurisdictional claims in published maps and institutional affiliations.

Copyright: (c) 2021 by the authors. Licensee MDPI, Basel, Switzerland. This article is an open access article distributed under the terms and conditions of the Creative Commons Attribution (CC BY) license (https:// creativecommons.org/licenses/by/ $4.0 /)$.
Simple Summary: In perihilar cholangiocarcinoma with vascular involvement, vascular resection to achieve margin-free status is being performed with increasing frequency despite controversial results. Morbidity, mortality, and overall survival are widely variable throughout the world. Vascular resections can include the portal vein alone, the hepatic artery alone, or combined resections. In some cases of locally advance disease, extended resections, such as hepatopancreatoduodenectomy or liver transplant, may be performed to achieve R0 status or a change to cure. The neoadjuvant treatment could help to achieve it. This article reviews and updates all treatment options in this setting.

Abstract: Among the cholangiocarcinomas, the most common type is perihilar (phCC), accounting for approximately $60 \%$ of cases, after which are the distal and then intrahepatic forms. There is no staging system that allows for a comparison of all series and extraction of conclusions that increase the long-term survival rate of this dismal disease. The extension of the resection, which theoretically depends on the type of phCC, is not a closed subject. As surgery is the only known way to achieve a cure, many aggressive approaches have been adopted. Despite extended liver resections and even vascular resections, margins are positive in around one third of patients. In the past two decades, with advances in diagnostic and surgical techniques, surgical outcomes and survival rates have gradually improved, although variability is the rule, with morbidity and mortality rates ranging from $14 \%$ to $76 \%$ and from $0 \%$ to $19 \%$, respectively. Extended hepatectomies and portal vein resection, or even right hepatic artery reconstruction for the left side tumors are frequently needed. Salvage procedures when arterial reconstruction is not feasible, as well as hepatopancreatoduodenectomy, are still under evaluation too. In this article, we discuss the aggressive surgical approach to phCC focused on vascular resection. Disparate results on the surgical treatment of phCC made it impossible to reach clear-cut conclusions.

Keywords: perihilar cholangiocarcinoma; vascular invasion in perihilar cholangiocarcinoma; biliary carcinoma; surgery in vascular involvement

\section{Introduction}

Altemeier in 1957 and Gerald Klatskin in 1965 were the first surgeons who described cholangiocarcinoma [1,2]. Between $50 \%$ and $70 \%$ of all cholangiocarcinomas are perihilar (phCC) or Klatskin tumors [3-6]. phCC is a highly unresectable malignancy because, despite being a slow growing tumor, its proximity to hepatic hilar structures leads to early vascular involvement, complicating surgical resection. Thus, most patients are diagnosed in an advanced stage of the disease which includes major vascular involvement. Surgical resection is the standard therapy for phCC and provides the only chance for cure in this disease. An aggressive surgical approach increases the number of resectable tumors that are initially regarded as unresectable [7], with 5-year survival rates (5-y SR) of 25-45\% in 
R0 resections and of $0-23 \%$ in R1 resections [3,4,8,9]. Vascular resections (VRs) of the portal vein (PV), the hepatic artery (HA), or both add postoperative morbidity and mortality, although they achieve a higher R0 resection rate (i.e., microscopically negative margin), which is the most important factor to get increasing overall survival [3,9] (Table 1).

Table 1. Vascular resection in phCC.

\begin{tabular}{|c|c|c|c|c|c|c|c|c|c|}
\hline Study & Year & Patients, $n$ & Vascular Resection, $n$ & Morbidity \% & Mortality \% & 5-y SV & Ro \% & R1 \% & R0 with VR\% \\
\hline Lygidakis et al. [10] & 1988 & 13 & 7 & NA & 15 & NA & NA & NA & 46 \\
\hline Edmond et al. [11] & 1989 & 13 & 5 & 69 & 15 & NA & NA & NA & 46 \\
\hline Klempnauer et al. [12] & 1997 & 125 & 41 & 29.8 & 9.9 & 28 & 26 & 6.8 & 73 \\
\hline Magriaga et al. [13] & 1998 & 28 & 9 & 32 & 14 & 8 & 11 & 0 & 50 \\
\hline Neuhaus et al. [14] & 1999 & 66 & 23 & 56 & 3 & 22 & 42 & 9 & 61 \\
\hline Lee et al. [15] & 2000 & 111 & 29 & 22 & 6.3 & 24 & NA & NA & 77 \\
\hline Nimura et al. [16] & 2000 & 142 & 43 & 48.6 & 9 & 25 & 26 & 16 & 61 \\
\hline Nagino et al. [17] & 2001 & 105 & 33 & 81 & 9.5 & NA & NA & NA & NA \\
\hline Munñoz et al. [18] & 2002 & 28 & 10 & 25 & 3 & 23 & NA & NA & NA \\
\hline Neuhaus et al. [19] & 2003 & 133 & NA & NA & NA & NA & 38 & 18 & NA \\
\hline Ebata et al. [20] & 2003 & 160 & 52 & 84 & 9.6 & 37 & NA & NA & NA \\
\hline Shimada et al. [21] & 2003 & 39 & 15 & 71 & 6.7 & 56 & 50 & 10 & 50 \\
\hline Kondo et al. [22] & 2004 & 42 & 14 & 48 & 0 & NA & NA & NA & 95 \\
\hline Hemming et al. [23] & 2005 & 53 & 23 & 40 & 9 & 35 & 45 & 0 & 80 \\
\hline Baton et al. [24] & 2007 & 59 & 5 & 42 & 5 & 20 & 28 & 6 & 67 \\
\hline Miyazaki et al. [25] & 2007 & 161 & 43 & 39 & 7 & NA & 36 & 0 & 36 \\
\hline Hidalgo et al. [26] & 2008 & 44 & 17 & 66 & 6.8 & 41 & 45 & 26 & 45 \\
\hline Song et al. [27] & 2009 & 259 & 51 & 54 & 9.6 & 29.3 & 29.3 & 17 & 71.8 \\
\hline Igami et al. [28] & 2010 & 298 & 111 & 43 & 2 & 42 & 52 & 32 & 66 \\
\hline Young et al. [29] & 2010 & 51 & 21 & 75 & 8 & 20 & 40 & 2 & 57 \\
\hline Miyazaki et al. [30] & 2010 & 107 & 25 & NA & 2 & NA & 33 & 21 & 59 \\
\hline Nagino et al. [31] & 2010 & 261 & 50 & 54 & 2 & 30 & 40.7 & 0 & 54 \\
\hline Hemming et al. [32] & 2011 & 95 & 42 & 36 & 5 & 43 & 50 & 0 & 84 \\
\hline All & 24 years & 2393 & 30.4 & 50.8 & 7.2 & 30.2 & 37 & 10.2 & 62 \\
\hline
\end{tabular}

phCC: perihilar cholangiocarcinoma; R0: R0 resection; VR: vascular resection; R1: R1 resection; NA: not applicable.

The aims of surgery in phCC are (1) to achieve the macroscopic removal of the tumor (VR increases the number of resected patients); (2) to satisfactorily restore bile flow to the gut; and (3) minimize postoperative liver failure or death. There are several surgical techniques to perform in these cases, since the extension of the resection depends on the radial extension of the tumor (leading to VR of the PV and/or HA), the longitudinal extension (if requiring a hepatopancreatoduodenectomy), or both (VR and hepatopancreatoduodenectomy) [3].

Advanced phCC requires extended liver resection and often VR, although margins may be affected in about one third of the patients [6]. Right-sided tumors, depending on their extension, often require extended right liver resections together with the PV, which is most optimally achieved with an en bloc resection or the Rex recess approach. Left-sided tumors frequently require extended left hepatectomy and often involve the contralateral $\mathrm{PV}$ or right $\mathrm{HA}$, due to their proximity to the biliary bifurcation, therefore making their reconstruction necessary. Right HA involvement is more frequent. Arterial infiltration of the contralateral side of the planned hepatic resection is a contraindication to surgical treatment, though not in all centers. In patients with $\mathrm{R} 0$ resections, in histological analysis, the portal involvement is present in $20-30 \%$, and its preoperative identification is achieved with an accuracy of $85 \%[14,18,20,27,31,33,34]$.

The conventional surgical technique for the treatment of phCC is right or left hepatectomy, plus segment 1 resection, plus biliary duct resection, plus hilar lymphadenectomy. To this technique, a PV resection alone, a HA resection alone, both (HA resection may be followed or not by a HA reconstruction or a PV arterialization), or a pancreatoduodenectomy can be added. Liver transplantation is also a possible treatment considered as a drastic vascular resection (Figure 1) [3,35-37].

If a consensus is not achieved on the surgical treatment of colorectal liver metastases, in the case of the treatment of pHCC, the final picture is even more complex [38]. Controversies arise regarding "on demand" or "elective" PV resection, HA resection in the remnant liver, left or right extended hepatectomy in Bismuth type IV, and liver transplant. Difficulties in analyzing the available data and the ability to draw clear conclusions on the efficacy of these treatments are due to the use of different classifications, both surgical 
(Bismuth and Corlette, 1975) and oncological (extension of tumor within the biliary tree, vascular invasion, lobar atrophy, and metastatic disease); heterogeneity of data and series, since many large series are limited to very specific areas; the number of different preoperative, postoperative, and histological staging classifications; large differences in the range of results; differences in neoadjuvant chemotherapy and radiotherapy protocols used in the last decades, and significant differences between Western and Eastern countries (even within the same country) in the management of vascular involvement.

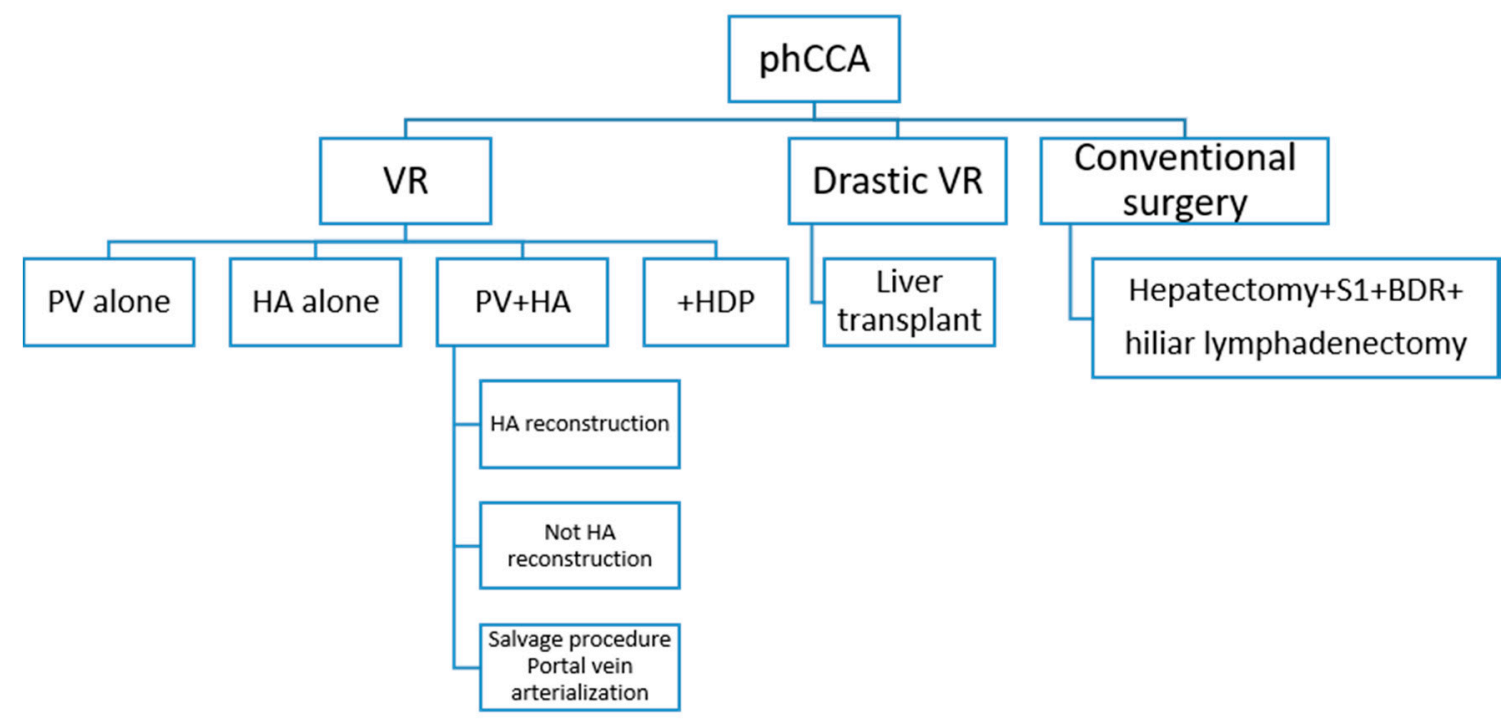

Figure 1. Vascular resections options. phCCA: perihilar cholangiocarcinoma; VR: vascular resection; PV: portal vein; HA: hepatic artery; HPD: hepatopancreatectoduodenectomy; S1: segment 1; BDR: biliary duct resection.

Several limitations should be considered when interpreting data, according to Liang's study. Although we only selected high-quality studies, all of them were predominantly retrospective in nature and, as such, there may be inherent selection bias. Additionally, heterogeneity in the selection of patients may have led to selection bias. Finally, some prognostic factors displayed significant heterogeneity [39].

There are notable differences between Western and Eastern countries in the use of PV embolization, PV resection, HA resection and even in the future remnant liver volume (FRL). All of them, except FRL, are more frequently performed in Eastern countries, with reported morbidities and mortalities lower than in Western ones [40]. Even in the same zone there are several differences too. Figure 2 shows great differences between two European hospitals.

In Europe, in experienced centers the 90-day postoperative mortality is more than $10 \%$. Around $48 \%$ of the patients die from post-hepatectomy liver failure [41,42]. In the largest center in Asia, the overall mortality was $4.7 \%$ for the period 1977-2010, decreasing sharply from $11.1 \%$ to $1.4 \%$ for the periods $1977-1990$ and 2006-2010, respectively, even after including patients with more locally advanced disease during the latter period [6]. The presence of Bismuth type IV phCC (involving both the right and left intrahepatic ducts) is no longer an absolute contraindication to complete resection, since it is associated with an overall survival (OS) similar to that of patients with less extensive biliary extension [43]. Moreover, resection and reconstruction of the PV and HA are increasingly performed $[9,33]$.

In an Australian study, there were a higher mortality and morbidity in the VR patient group, and these two rates increased when HA resection was performed [33]. The overall series had $50.8 \%$ morbidity and $7.2 \%$ mortality, but VR was only done in $29.6 \%$ of the cases. The authors concluded that PV invasion did not preclude the curative resection and that it should be performed in case of PV involvement. 
Miguel Servet Series 2012-2019

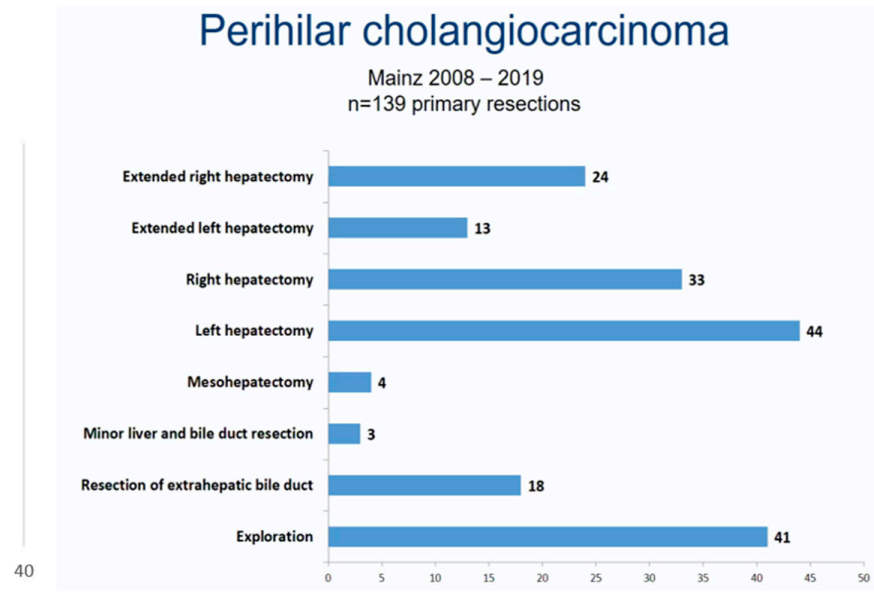

Figure 2. Miguel Servet/Mainz Series.

\section{Portal Vein Resection}

True PV invasion in phCC is difficult to determine preoperatively. When computed tomography is analyzed, vessel constriction, loss of a clear plane, and occlusion are considered evidence of venous invasion.

Left PV resection is not a technically complex procedure. Usually, end-to-end anastomosis is possible with or without graft interposition, autologous or not. Grafting is necessary when the length of resection is more than $5 \mathrm{~cm}$ however, since the left PV has a long extrahepatic path and there is an easy access to the vein into the umbilical fissure, it is almost always possible to avoid grafting [43-45]. Generally, there is not much difference in diameter between both ends, and it is possible to perform a standard anastomosis.

The right PV is short and bifurcates early in its course. The limits of right PV resection depend on whether the first branches can be controlled with clamps. A Y graft may be necessary. There are discrepancies in the diameters of the main PV and the right branches (especially between the right posterior sector branch and the main PV) $[43,46]$. The Rex recess approach includes a right hepatectomy with en bloc resection of the hepatoduodenal ligament and PV reconstruction to the left portal vein at the Rex recess [43,45].

In general, PV bifurcation should be resected only when tumor adherence or infiltration has been detected or when it seems to be invaded. The Nehaus team's practice of PV resection a priori has not yet been validated. In 2019, Higuchi et al. found that the absence of neoplastic invasion of the vein in histological analysis was a good prognostic factor compared with the presence of high dysplasia or in situ tumor [47]. In 2018, van Vugt et al. concluded that both unilateral and main HA involvement are independent poor prognostic factors for overall survival, whereas PV involvement is not [48]. Actual rates of venous invasion on histopathological examination after resection vary from $21 \%$ to $80 \%$ according to Abbas's meta-analysis [33].

The point of controversy regarding portal vein resection is whether it is performed systematically or on demand, based on the radiological and intraoperative findings [49]. In 2012, Nehaus compared two groups of 50 patients each, one with en bloc resection of the PV and the other with only major hepatectomy. The first group had a better survival rate than the second group. Although evaluation of short-term results failed to reveal any association between combined PV resection and a high postoperative complication rate, a correlation between PV resection and a higher mortality was identified [49]. The mean mortality rate of combined PV resection is lower in studies with larger sample sizes, and was also lower in studies published after 2008. Liver failure was and is the main cause of postoperative mortality, although the management of jaundice with percutaneous drainage and improvements in anesthesia management have decreased mortality in the last decade.

Ebata et al. found that macroscopic portal vein invasion was a poor prognostic factor [20]. In the Netherland group, Rassam et al. in 2018 showed that $20 \%$ of their cases 
had PV resection, with a $44.3 \%$ 5-y SR, similar to $43 \%$ in the Berlin group of R0 resections using unconditional en bloc resection [50].

We can conclude that, currently, on demand PV resection has the same survival rate as resection en bloc, so the decision on whether to resect the PV or not should be made in the operating theatre. PV resection increases the survival rate, but has significantly high rates of morbidity and mortality depending on centers. De Jong et al. analyzed 305 patients, with PV resection performed in $16.7 \%$ of them. Thirty- and ninety-day mortality was more that four-fold higher in this group, compared with the non-vascular resected group [9].

\section{Hepatic Artery Resection}

The right hepatic artery is closely associated with posterior or anterior surface of the biliary confluence and is often involved by tumors, but its preservation is utterly important for the remnant liver after left or extended left hepatectomies. R0 resections requiring resection and reconstruction of an involved artery are associated with high morbidity and mortality [33]. The left hepatic artery is infrequently involved by tumors because it runs well away from the biliary confluence, therefore in extended right hepatectomy it is rare to need hepatic artery reconstruction. The rate of positive involvement in the resected hepatic artery is lower than in the resected portal vein (PV 47.1\% and HA 40\%) [46].

Arterial resection and reconstruction are usually performed in a left-sided resection (IIIb) for anatomical reasons. Most reports show dismal results: Gerhads et al. reported a 55.6\% mortality; Ota et al. stated a $46.9 \%$ mortality, but their series was about HPD; Yamanaka et al. reported a 10\% mortality but 90\% morbidity; Shimada et al. reported a mortality with HA resection and reconstruction of $13.3 \%$ vs. $8.3 \%$ without it; Sakamoto et al. reported 0\% mortality, and Miyazaki et al. stated a 33\% mortality and 0\% 3-y SR in patients with HA resection [21,25,51-54].

The inflection point of the current improvement in surgical techniques lies in the knowledge derived from living donor liver transplant techniques, since they have been key to improving these data. After 2010, outcomes began to be better than before (Table 2).

Table 2. Arterial resection in phCC.

\begin{tabular}{|c|c|c|c|c|c|c|c|c|}
\hline Author & Year & Cases & $\begin{array}{c}\text { Hepatic Left } \\
\text { Trisectionectomy }\end{array}$ & $\begin{array}{l}\text { Hepatic Right } \\
\text { Trisectionectomy }\end{array}$ & $\underset{\text { PVR }}{\text { Simultaneous }}$ & Morbidity (\%) & Mortality (\%) & 5-y SV \\
\hline Nagino et al. [31] & 2010 & 50 & $26(52 \%)$ & 0 & $50(100 \%)$ & 54 & 2 & 30 \\
\hline Wang et al. [55] & 2015 & 24 & 0 & 0 & $18(75 \%)$ & 42 & 4 & 25 \\
\hline Matsuyama et al. [56] & 2016 & 44 & $22(50 \%)$ & 0 & $24(55 \%)$ & 66 & 9 & 22 \\
\hline Noji et al. [57] & 2016 & 28 & $7(25 \%)$ & 0 & $23(82 \%)$ & 57 & 4 & 26 \\
\hline Peng et al. [58] & 2016 & 26 & 0 & 0 & $2(8 \%)$ & 19 & 8 & 31 \\
\hline Hu et al. [59] & 2018 & 63 & $12(19 \%)$ & $3(1 \%)$ & $35(56 \%)$ & 19 & 3 & 22 \\
\hline Schimizzi et al. [60] & 2018 & 12 & $\begin{array}{c}0 \\
0\end{array}$ & $1(8 \%)$ & $2(17 \%)$ & 67 & 8 & - \\
\hline Higuchi et al. [47] & 2018 & 19 & $1(5 \%)$ & 0 & $12(63 \%)$ & 47 & 16 & 16 \\
\hline Kotenko et al. [61] & 2019 & 13 & NA & NA & $13(100 \%)$ & NA & 9.3 & 18.8 \\
\hline Mizuno et al. [62] & 2020 & 146 & 86 (59\%) & $1(1 \%)$ & $100(68 \%)$ & 51 & 4 & 27 \\
\hline All & & 425 & $154(37.4 \%)$ & $5(1.2 \%)$ & $277(65.1 \%)$ & 0.47 & 7.5 & 27.2 \\
\hline
\end{tabular}

PVR: portal vein resection; phCC: perihilar cholangiocarcinoma; NA: not applicable.

In a series from 2010 to 2020 with 425 patients, 37.4\% had an extended left hepatectomy, $1.2 \%$ an extended right hepatectomy, and $65.1 \%$ a combined PV resection. Morbidity was $47 \%$, mortality was $7.5 \%$ and the 5-y SR was $27.2 \%$. All these data come from the higher quality Asian groups.

Nagino et al. did not find statistically significant differences associating VR or pancreatoduodenectomy. However, despite these aggressive procedures, the circumferential margin was positive in $34 \%$ of the patients and $50 \%$ of them had nodal involvement, although they reported a 1,3, and 5-y SR of $78.9 \%, 36.3 \%$, and 30.3\%, respectively [62,63]. They defended HA resections when they analyzed unresected patients in comparation with arterial and/or portal vein resections.

Some surgical refinements have been proposed. The De Santibañes et al. and lida et al. groups gave the surgeon the possibility of creating a satisfactory anastomosis before the resection began and the possibility of abandoning the procedure if it was not feasible $[64,65]$. 
As Bismuth type IIIB often requires a major left hepatic resection and invasion of the right HA usually contraindicates the procedure, they proposed performing a HA reconstruction between the posterior branch of the right HA and the left HA as the first surgical step, before transection of the parenchyma and the hilar resection. Uchiyama et al., in an excellent technical article, tried to standardize PV resection and HA resection in extended left hepatectomy, although perhaps this complex surgery should be centralized in specific groups [66].

We can decide not to perform a right HA reconstruction. This is possible when the right $\mathrm{HA}$ or one of the right hepatic arteries come from the superior mesentery artery, or when, in patients undergoing left-sided resections involving RHA, the liver is minimally mobilized to preserve the collaterals. Some surgeons prefer to embolize the proper HA, or the left or right $\mathrm{HA}$, to stimulate growth of collateral arteries, but this procedure carries a great risk of ischemia [67-69].

van Vugt et al. concluded that HA involvement (one or both) was a poor prognostic factor but that the PV involvement was not [48]. Govil et al. concluded that a way to perform a safer and potentially curative surgery in extended left liver resections by phCC is to have experience in performing safe arterial resection and reconstruction [70]. This, in turn, increases the resectability rate for pHCC, particularly for Bismuth-Corlette type IV tumors.

If both the PV and HA are involved, resection and reconstruction of both can be performed. PV anastomosis should be performed first if both are resected [62].

The complications of arterial resections and reconstructions are bleeding and thrombosis with deleterious effects to liver parenchyma, pseudoaneurysms, or aneurysms.

\section{Vascular Resection and Hepatopancreatoduodenectomy}

We can find deeply differing results between Eastern and Western countries regarding survival rate. Nagino et al. in 2021 showed a 5-y SR of 37\% but Souza et al. in 2021 reported a lower SR and a 17\% 90-day mortality [63,70,71].

In Nagino's series, patients were a mean of 60 years old. Most of the combined VRs and HPDs were performed with extended left hepatectomy [63]. PV reconstruction was performed with external iliac venous graft and HA reconstruction with end-to-end anastomosis except in two cases (one with portal vein arterialization and one using the radial artery). Despite this huge surgical tour de force, R1 resection was present in $45 \%$ of the cases, although the 5-y SR was $37 \%$. In the study by Ebata et al. in 2014, hepaticopancreatoduodenectomy combined with VR was a poor prognostic factor, together with histological status [36].

Due to the complexity of the surgery and its high morbidity and mortality, in addition to the dispersion of the data and the concentration of the series in a few centers, no conclusion can be drawn.

\section{Portal Vein Arterialization (PVA)}

PV arterialization has been used as a salvage procedure when arterial reconstruction fails during surgery, with a success rate of around $60 \%$. In the series from the Paul Brousse Hospital, there were 4 intrahospital deaths and 10 deaths between 2 and 30 months of follow-up out of 16 patients. Complications related with this procedure are hyperbilirubinemia and hemorrhage due to portal hypertension. At times we have needed to urgently embolize this shunt due to uncontrolled hemorrhage [72]. We performed this procedure during extended left hepatectomy with curative intention except in one patient $(25 \%)$, in whom the shunt was performed during the postoperative course as an emergency surgery, with a mortality of $50 \%$. If the liver does not totally mobilize, the hepatic artery could not be reconstructed with uncertain results. Furthermore, portal vein arterialization should be closed by interventional radiologists to avoid right heart failure (Table 3).

Making conclusions in this setting is very difficult, because PV arterialization is usually an unplanned approach, even a rescue procedure and, although it is a technique that hepato-pancreato-biliary surgeons must know, its results are difficult to predict. 
Table 3. Portal vein arterialization.

\begin{tabular}{|c|c|c|c|c|c|c|}
\hline \multirow{2}{*}{ Hospital } & \multirow{2}{*}{ Age/Sex } & Hepatobiliary Surgery & \multirow{2}{*}{ Primary Procedure } & Portal Vein Arterialization & \multirow{2}{*}{ Timing } & \multirow{2}{*}{ Type } \\
\hline & & Indication for Surgery & & Indication for PVA and Timing & & \\
\hline Paul Brousse & $61 / \mathrm{M}$ & $\begin{array}{c}\text { Hilar cholangiocarcinoma (Klatskin } \\
\text { type IIIB) }\end{array}$ & $\begin{array}{l}\text { Left extended hepatectomy } \\
\text { (including segments I, V, VIII) }\end{array}$ & $\begin{array}{c}\text { For curative resection (RHA } \\
\text { involvement) }\end{array}$ & During LR & CHA to PV \\
\hline Miguel Servet & $56 / \mathrm{M}$ & $\begin{array}{l}\text { Hilar cholangiocarcinoma (Klatskin } \\
\text { type IIIB) }\end{array}$ & $\begin{array}{l}\text { Left extended hepatectomy } \\
\text { (including segments I, V, VIII) }\end{array}$ & $\begin{array}{l}\text { For HA thrombosis (LHA to RPHA). } \\
\text { Salvage procedure }\end{array}$ & 20th POD & PHA to PV \\
\hline Miguel Servet & $71 / \mathrm{F}$ & $\begin{array}{l}\text { Hilar cholangiocarcinoma (Klatskin } \\
\text { type IIIB) }\end{array}$ & $\begin{array}{l}\text { Left extended hepatectomy } \\
\text { (including segments I, V) }\end{array}$ & $\begin{array}{c}\text { For curative resection (RHA } \\
\text { involvement) }\end{array}$ & During LR & PHA to PV \\
\hline Miguel Servet & $68 / \mathrm{F}$ & $\begin{array}{l}\text { Hilar cholangiocarcinoma (Klatskin } \\
\text { type IIIB) }\end{array}$ & $\begin{array}{l}\text { Left extended hepatectomy } \\
\text { (including segment I) }\end{array}$ & $\begin{array}{c}\text { For curative resection (RHA } \\
\text { involvement) }\end{array}$ & During LR & PHA to PV \\
\hline Miguel Servet & $74 / \mathrm{F}$ & $\begin{array}{c}\text { Hilar cholangiocarcinoma (Klatskin } \\
\text { type IIIB) }\end{array}$ & $\begin{array}{l}\text { Left extended hepatectomy } \\
\text { (including segments I, V, VIII) }\end{array}$ & $\begin{array}{l}\text { For postoperative complication with } \\
\text { pseudoaneurysm } 21 \text { POD. Rescue } \\
\text { after hepatic artery reconstruction }\end{array}$ & 21st POD & CHA to PV \\
\hline Shizuoka General & $64 / \mathrm{M}$ & $\begin{array}{l}\text { Hilar cholangiocarcinoma (Klatskin } \\
\text { type IIIB) }\end{array}$ & $\begin{array}{l}\text { Extended left LR + PD with RHA } \\
\text { excision/ reconstruction }\end{array}$ & Post op HAT in reconstructed artery & $1 \mathrm{POD}$ & $\begin{array}{l}\text { Mesenteric vascular } \\
\text { branches (ileal) }\end{array}$ \\
\hline Shizuoka General & $72 / \mathrm{F}$ & $\begin{array}{c}\text { Hilar cholangiocarcinoma (Klatskin } \\
\text { type IIIa) }\end{array}$ & Extended right LR & $\begin{array}{l}\text { Postoperative ligation of CHA } \\
\text { following HAP rupture (day 6) } \\
\text { causing massive liver necrosis }\end{array}$ & 7th POD & $\begin{array}{c}\text { First PVA-mesenteric } \\
\text { vascular branches (ileocecal) }\end{array}$ \\
\hline Shizuoka General & $65 / \mathrm{M}$ & $\begin{array}{l}\text { Hilar cholangiocarcinoma (Klatskin } \\
\text { type IIIB) }\end{array}$ & $\begin{array}{l}\text { PD, extended left LR, excision of } \\
\text { anterior branch RHA }\end{array}$ & $\begin{array}{c}\text { For curative surgery (pre-emptive } \\
\text { shunt) }\end{array}$ & $\begin{array}{l}5 \text { days before major } \\
\text { resection }\end{array}$ & $\begin{array}{l}\text { Mesenteric vascular } \\
\text { branches (ileal) }\end{array}$ \\
\hline Hokkaido University & $56-81$ & Hilar cholangiocarcinoma (6) & $\begin{array}{c}\text { Major liver resection with en bloc } \\
\text { HA resection }\end{array}$ & For curative surgery & During LR & GDA or CHA to PV \\
\hline St James's University & $54 / \mathrm{M}$ & Hilar cholangiocarcinoma & LR & For curative surgery & During LR & GDA to PV \\
\hline St James's University & $51 / \mathrm{F}$ & Hilar cholangiocarcinoma & LR & For curative surgery & During LR & RHA to PV \\
\hline $\begin{array}{l}\text { General Hospital of } \\
\text { Chinese People's } \\
\text { Liberation Army }\end{array}$ & $50-54$ & Hilar cholangiocarcinoma (3) & LR & For curative surgery & During LR & HA to PV (with calibration) \\
\hline West China Hospital & $55 / \mathrm{M}$ & Hilar cholangiocarcinoma & LR & For curative surgery & During LR & GDA to PV \\
\hline
\end{tabular}

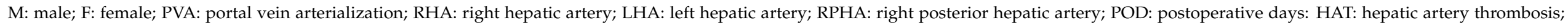

CHA: common hepatic artery; PHA: proper hepatic artery; LR: liver resection; PD: pancreatoduodenectomy; GDA: gastroduodenal artery; PV: portal vein; HA: hepatic artery. 


\section{Liver Transplantation (LT)}

Liver transplantation is the most radical procedure in terms of vascular resections. Under strict conditions, LT may be offered in unresectable phCCs in patients with (1) a malignant appearing stricture and at least one of the following: malignant cytology or histology; CA-19.9 >130 U/mL without cholangitis; polysomy on fluorescence in situ hybridization; a mass on cross-sectional imaging $\leq 3 \mathrm{~cm}$ and no extrahepatic disease; (2) a cancer located primarily above the cystic duct; and (3) an unresectable cancer de novo phCCA or cancer arising in the setting of primary sclerosing cholangitis [73].

Loveday et al. reported one- and two-year post-transplant overall survival of $83.3 \%$ and 55.6\%, respectively, in intention-to-treat patients [74]. In the European Liver Transplant Register's experience, Mantel et al. reported a 59\% $5 \mathrm{y}$-SR in patients within the Mayo Clinic criteria and only $21 \%$ in those beyond it. Therefore, the authors advocated that the selection criteria should be within the Milan protocol [75].

In 2018, Ethun et al. defended the premise that patients with resectable phCC would obtain superior survival with liver resection compared to liver transplantation had changed. The authors, in their prospective observational study, sought to validate the results after following the Mayo Clinic protocol for orthotopic LT for "unresectable disease", and to compare them with the results after hepatectomy for "resectable" phCCA [76]. The transplant group achieved a much better 5-y SR with $64 \%$ compared to $18 \%$ in the group that was resected $(p<0.001)$, despite having inoperable or more advanced disease [76].

In the Transplant Oncology Consensus Conference 2020, the agreed conclusions were that LT for phCC is an acceptable indication, that patients should undergo neoadjuvant chemoradiation prior to LT, that the inclusion criteria for LT should be based on the Mayo Clinic criteria, and that, due to organ allocation issues, living donor liver transplant, if possible, is the preferred option.

\section{Conclusions}

We can conclude (1) that advanced pHCC requires an extended hepatic resection and frequently a vascular resection too; (2) extended right hepatectomy in right-sided tumors is likely to need PV resection with end-to-end anastomosis or a Rex recess approach; (3) PV resection increases morbidity and mortality but achieves R0 resection more frequently and should be performed "on demand"; (4) extended left hepatectomy in left-sided tumors is likely to need PV resection as well as HA resection to achieve an R0 resection; (5) arterial reconstruction causes more morbidity and mortality and its oncological benefits are unclear; (6) HPD with VR should be performed in high level centers and in very select patients; (7) PV arterialization is a salvage procedure with uncertain outcomes; and (8) liver transplant could be key to rescuing more patients with vascular involvement within the Mayo Clinic/Toronto Protocol.

Author Contributions: Conceptualization, A.S.; methodology, A.S. and L.S.; software, L.S.; validation, A.S., L.S., R.A. and L.T.; writing—original draft preparation, A.S. and L.S.; writing—review and editing, L.T.; visualization, L.S. and A.S.; supervision, A.S. and R.A. All authors have read and agreed to the published version of the manuscript.

Funding: This research received no external funding.

Conflicts of Interest: The authors declare no conflict of interest.

\section{References}

1. Altameier, W.A.; Gall, E.A.; Zinninger, M.M.; Hoxworth, P.I. Sclerosing carcinoma of the major intrahepatic bile ducts. AMA Arch. Surg. 1957, 75, 450-460. [CrossRef]

2. Klatskin, G. Adenocarcinoma of hepatic duct at its bifurcation within Porta Hepatis. An usual tumor with distinctive clinical and pathological features. Am. J. Med. 1965, 38, 241-256. [CrossRef]

3. Serrablo, A.; Tejedor, L. Outcome of surgical resection in Klatskin tumors. World J. Gastrointest. Oncol. 2013, 15, 147-158. [CrossRef] 
4. De Oliveira, M.L.; Cunningham, S.C.; Cameron, J.L.; Kamangar, F.; Winter, J.M.; Lillemoe, K.D.; Choti, M.A.; Yeo, C.J.; Schulick, R.D. Cholangiocarcinoma: Thirty-one-year experience with 564 patients at a single institution. Ann. Surg. 2007, 245, 755-762. [CrossRef]

5. Ebata, T.; Kosuge, T.; Hirano, S.; Unno, M.; Yamamoto, M.; Miyazaki, M.; Kokudo, N.; Miyagawa, S.; Takada, T.; Nagino, M. Proposal to modify the international union against cancer staging system for perihilar cholangiocarcinomas. J. Br. Surg. 2014, 101, 79-88. [CrossRef] [PubMed]

6. Nargoney, D.M.; Pawlik, T.M.; Chun, Y.S. AJCC Cancer Staging Manuel, 8th ed.; Springer: Berlin/Heidelberg, Germany, 2017.

7. Nagino, M.; Ebata, T.; Yokoyama, Y.; Igami, T.; Sugawara, G.; Takahashi, Y.; Nimura, Y. Evolution of surgical treatment for perihilar cholangiocarcinoma a single-center 34-year review of 574 consecutive resections. Ann. Surg. 2013, 258, 129-140. [CrossRef] [PubMed]

8. Capobianco, I.; Rolinger, J.; Nadalin, S. Resection for klatskin tumors: Technical complexities and results. Transl. Gastroenterol. Hepatol. 2018, 3, 69. [CrossRef] [PubMed]

9. De Jong, M.C.; Marques, H.; Clar, B.M.; Bauer, T.W.; Marsh, J.W.; Ribero, D.; Majno, P.; Hatzaras, I.; Walters, D.M.; Barbas, A.S.; et al. The impact of portal vein resection on outcomes for hilar cholangiocarcinoma a multi-institutional analysis of 305 cases. Cancer 2012, 118, 4737-4747. [CrossRef] [PubMed]

10. Lygidakis, N.L.; van der Heyde, M.N.; van Dongen, R.J.; Kromhout, J.G.; Tytgat, G.N.; Huibregtse, K. Surgical approaches for unresectable primary carcinoma of the hepatic hilus. Surg. Gynecol. Obstet. 1988, 166, 107-114.

11. Edmond, J.C.; Mayes, T.; Rouch, D.A.; Thistlethwaite, J.R.; Broelsch, C.E. Experience with resection in the management of proximal bile duct cancer. HPB Surg. 1989, 1, 297-307. [CrossRef]

12. Klempnauer, J.; Ridder, G.J.; Werner, M.; Weimann, A.; Pichlmayr, R. What constitutes long-term survival after surgery for hilar cholangiocarcinoma? Cancer 1997, 79, 26-34. [CrossRef]

13. Madariaga, J.R.; Iwatsuki, S.; Todo, S.; Lee, R.G.; Irish, W.; Starzl, T.E. Liver resection for hilar and peripheral cholangiocarcinomas: A study of 62 cases. Ann. Surg. 1998, 227, 70-79. [CrossRef]

14. Neuhaus, P.; Jonas, S.; Bechstein, W.; Lohmann, R.; Radke, C.; Kling, N.; Wex, C.; Lobeck, H.; Hintze, R. Extended resections for hilar cholangiocarcinoma. Ann. Surg. 1999, 230, 808. [CrossRef]

15. Lee, S.G.; Lee, Y.J.; Park, K.M.; Hwang, S.; Min, P.C. One hundred and eleven liver resections for hilar bile duct cancer. J. Hepato-Biliary-Pancreat. Surg. 2000, 7, 135-141. [CrossRef]

16. Nimura, Y.; Kamiya, J.; Kondo, S.; Nagino, M.; Uesaka, K.; Oda, K.; Sano, T.; Yamamoto, H.; Hayakawa, N. Aggressive preoperative management and extended surgery for hilar cholangiocarcinoma: Nagoya experience. J. Hepato-Biliary-Pancreat. Surg. 2000, 7, 155-162. [CrossRef] [PubMed]

17. Nagino, M.; Ando, M.; Kamiya, J.; Uesaka, K.; Sano, T.; Nimura, Y. Liver regeneration after major hepatectomy for biliary cancer. J. Br. Surg. 2002, 88, 1084-1091. [CrossRef] [PubMed]

18. Muñoz, L.; Roayaie, S.; Maman, D.; Fishbein, T.; Sheiner, P.; Emre, S.; Miller, C.; Schwartz, M.E.; Muñoz-Bellvis, L. Hilar cholangiocarcinoma involving the portal vein bifurcation: Long-term results after resection. J. Hepato-Biliary-Pancreat. Surg. 2002, 9, 237-241. [CrossRef] [PubMed]

19. Neuhaus, P.; Jonas, S.; Settmacher, U.; Thelen, A.; Benckert, C.; Lopez-Hänninen, E.; Hintze, R.E. Surgical management of proximal bile duct cancer: Extended right lobe resection increases resectability and radicality. Langenbecks Arch. Surg. 2003, 388, 194-200. [CrossRef] [PubMed]

20. Ebata, T.; Nagino, M.; Kamiya, J.; Uesaka, K.; Nagasaka, T.; Nimura, Y. Hepatectomy with portal vein resection for hilar cholangiocarcinoma: Audit of 52 consecutive cases. Ann. Surg. 2003, 238, 720-727. [CrossRef] [PubMed]

21. Shimada, H.; Endo, I.; Sugita, M.; Masunari, H.; Fujii, Y.; Tanaka, K.; Misuta, K.; Sekido, H.; Togo, S. Hepatic resection combined with portal vein or hepatic artery reconstruction for advanced carcinoma of the hilar bile duct and gallbladder. World J. Surg. 2003, 27, 1137-1142. [CrossRef] [PubMed]

22. Kondo, S.; Hirano, S.; Ambo, Y.; Tanaka, E.; Okushiba, S.; Morikawa, T.; Katoh, H. Forty consecutive resections of hilar cholangiocarcinoma with no postoperative mortality and no positive ductal margins: Results of a prospective study. Ann. Surg. 2004, 240, 95-101. [CrossRef]

23. Hemming, A.W.; Reed, A.I.; Fujita, S.; Foley, D.P.; Howard, R.J. Surgical management of hilar cholangiocarcinoma. Ann. Surg. 2005, 241, 693-702. [CrossRef]

24. Baton, O.; Azoulay, D.; Adam, D.V.R.; Castaing, D. Major hepatectomy for hilar cholangiocarcinoma type 3 and 4: Prognostic factors and longterm outcomes. J. Am. Coll. Surg. 2007, 204, 250-260. [CrossRef] [PubMed]

25. Miyazaki, M.; Kato, A.; Ito, H.; Kimura, F.; Shimizu, H.; Ohtsuka, M.; Yoshidome, H.; Yoshitomi, H.; Furukawa, K.; Nozawa, S. Combined vascular resection in operative resection for hilar cholangiocarcinoma: Does it work or not? Surgery 2007, 141, 581-588. [CrossRef] [PubMed]

26. Hidalgo, E.; Asthana, S.; Nishio, H.; Wyatt, J.; Toogood, G.; Prasad, K.; Lodge, J. Surgery for hilar cholangiocarcinoma: The leeds experience. Eur. J. Surg. Oncol. 2008, 34, 787-794. [CrossRef]

27. Song, G.-W.; Lee, S.-G.; Hwang, S.; Kim, K.-H.; Cho, Y.-P.; Ahn, C.-S.; Moon, D.-B.; Ha, T.-Y. Does portal vein resection with hepatectomy improve survival in locally advanced hilar cholangiocarcinoma? Hepatogastroenterology 2009, 56, 935-942.

28. Igami, T.; Nishio, H.; Ebata, T.; Yokoyama, Y.; Sugawara, G.; Nimura, Y.; Nagino, M. Surgical treatment of hilar cholangiocarcinoma in the "new era": The Nagoya University experience. J. Hepato-Biliary-Pancreat. Sci. 2010, 17, 449-454. [CrossRef] 
29. Young, A.L.; Prasad, K.R.; Toogood, G.J.; Lodge, J.P. Surgical treatment of hilar cholangiocarcinoma in a new era: Comparison among leading Eastern and Western centres, Leeds. J. Hepato-Biliary-Pancreat. Sci. 2010, 17, 497-504. [CrossRef] [PubMed]

30. Miyazaki, M.; Kimura, F.; Shimizu, H.; Yoshidome, H.; Otuka, M.; Kato, A.; Yoshitomi, H.; Furukawa, K.; Takeuchi, D.; Takayashiki, T.; et al. One hundred seven consecutive surgical resections for hilar cholangiocarcinoma of bismuth types II, III, IV between 2001 and 2008. J. Hepato-Biliary-Pancreat. Sci. 2010, 17, 470-475. [CrossRef]

31. Nagino, M.; Nimura, Y.; Nishio, H.; Ebata, T.; Igami, T.; Matsushita, M.; Nishikimi, N.; Kamei, Y. Hepatectomy with simultaneous resection of the portal vein and hepatic artery for advanced perihilar cholangiocarcinoma: An audit of 50 consecutive cases. Ann. Surg. 2010, 252, 115-123. [CrossRef]

32. Hemming, A.W.; Mekeel, K.; Khanna, A.; Baquerizo, A.; Kim, R.D. Portal vein resection in management of hilar cholangiocarcinoma. J. Am. Coll. Surg. 2011, 212, 604-613. [CrossRef]

33. Abbas, S.; Sandroussi, C. Systematic review and meta-analysis of the role of vascular resection in the treatment of hilar cholangiocarcinoma. HPB 2013, 15, 492-503. [CrossRef]

34. Miyazaki, M.; Kimura, F.; Shimizu, H.; Yoshidome, H.; Ohtsuka, M.; Kato, A.; Yoshitomi, H.; Nozawa, S.; Furukawa, K.; Mitsuhashi, N.; et al. Recent advance in the treatment of hilar cholangiocarcinoma: Hepatectomy with vascular resection. J. Hepatobiliary Pancreat. Surg. 2007, 14, 463-468. [CrossRef]

35. Seyama, Y.; Makuuchi, M. Current surgical treatment for bile duct cancer. World J. Gastroenterol. 2007, 13, 1505-1515. [CrossRef]

36. Ebata, T.; Yokohama, Y.; Igami, T.; Sugawara, G.; Mizuno, T.; Nagino, M. Review of hepatopancreatoduodenectomy for biliary cancer: An extended radical approach of Japanese origin. J. Hepato-Biliary-Pancreat. Sci. 2014, 21, 550-555. [CrossRef] [PubMed]

37. Nagino, M. Cutting edge of an aggressive surgical approach for perihilar cholangiocarcinoma. Updat. Surg. 2013, 65, 81-83. [CrossRef] [PubMed]

38. Ignatavicius, P.; Oberkofler, C.E.; Chapman, W.C.; DeMatteo, R.P.; Clary, B.M.; D’Angelica, M.I.; Tanabe, K.K.; Hong, J.C.; Aloia, T.A.; Pawlik, T.M.; et al. Choices of therapeutic strategies for colorectal liver metastases among expert liver surgeons: A throw of the dice? Ann. Surg. 2020, 272, 715-722. [CrossRef] [PubMed]

39. Liang, L.; Li, C.; Jia, H.-D.; Diao, Y.-K.; Xing, H.; Pawlik, T.M.; Lau, W.Y.; Shen, F.; Huang, D.-S.; Zhang, C.-W.; et al. Prognostic factors of resectable perihilar cholangiocarcinoma: A systematic review and meta-analysis of high-quality studies. Ther. Adv. Gastrointest. Endosc. 2021, 14, 1-15. [CrossRef]

40. Olthof, P.B.; Miyasaka, M.; Koerkamp, B.G.; Wiggers, J.K.; Jarnagin, W.R.; Noji, T.; Hirano, S.; van Gulik, T.M. A comparison of treatment and outcomes of perihilar cholangiocarcinoma between Eastern and Western centers. HPB 2019, 21, 345-351. [CrossRef]

41. Farges, O.; Regimbeau, J.M.; Fuks, D.; Le Treut, Y.P.; Cherqui, D.; Bachellier, P.; Mabrut, J.Y.; Adham, M.; Pruvot, F.R.; Gigot, J.F. Multicentre European study of preoperative biliary drainage for hilar cholangiocarcinoma. J. Br. Surg. 2012, 100, $274-283$. [CrossRef]

42. Nuzzo, G.; Giuliante, F.; Ardito, F.; Giovannini, I.; Aldrighetti, L.; Belli, G.; Bresadola, F.; Calise, F.; Dalla Valle, R.; D’ Amico, D.F.; et al. Improvement in perioperative and long-term outcome after surgical treatment of hilar cholangiocarcinoma: Results of an Italian multicenter analysis of 440 patients. Arch. Surg. 2012, 147, 26-34. [CrossRef]

43. Ebata, T.; Mizuno, T.; Yokoyama, Y.; Igami, T.; Sugawara, G.; Nagino, M. Surgical resection for bismuth type IV perihilar cholangiocarcinoma. J. Br. Surg. 2018, 105, 829-838. [CrossRef]

44. Rela, M.; Rajalingam, R.; Shanmugam, V.; O’ Sullivan, A.; Reddy, M.S.; Heaton, N. Novel en-bloc resection of locally advanced hilar cholangiocarcinoma: The Rex recess approach. Hepatobiliary Pancreat. Dis. Int. 2014, 13, 93-97. [CrossRef]

45. Lahat, E.; Jaber, A.; Salloum, C.; Lim, C.; Golan, G.; Ben-Ari, Z.; Gutman, M.; Azoulay, D. Porto-rex shunt for left portal vein reconstruction during right extended hepatectomy for advanced extrahepatic biliary cancer. World J. Surg. 2019, 43, 1117-1120. [CrossRef] [PubMed]

46. Govil, S.; Reddy, M.S.; Rela, M. Surgical resection techniques for locally advanced hilar cholangiocarcinoma. Langenbeck's Arch. Surg. 2014, 399, 707-716. [CrossRef] [PubMed]

47. Higuchi, R.; Yazawa, T.; Uemura, S.; Izumo, W.; Ota, T.; Kiyohara, K.; Furukawa, T.; Egawa, H.; Yamamoto, M. Surgical outcomes for perihilar cholangiocarcinoma with vascular invasion. J. Gastrointest. Surg. 2018, 23, 1443-1453. [CrossRef] [PubMed]

48. van Vugt, J.L.A.; Gaspersz, M.P.; Coelen, R.J.S.; Vugts, J.; Labeur, T.A.; de Jonge, J.; Polak, W.G.; Busch, O.R.C.; Besselink, M.G.; IJzermans, J.N.M.; et al. The prognostic value of portal vein and hepatic artery involvement in patients with perihilar cholangiocarcinoma. HPB 2018, 20, 83-92. [CrossRef]

49. Neuhaus, P.; Thelen, A.; Jonas, S.; Puhl, G.; Denecke, T.; Veltzke-Schlieker, W.; Seehofer, D. Oncological superiority of hilar en bloc resection for the treatment of hilar cholangiocarcinoma. Ann. Surg. Oncol. 2021, 19, 1602-1608. [CrossRef]

50. Rassam, F.; Roos, E.; van Lienden, K.P.; van Hooft, J.E.; Klümpen, H.J.; van Tienhoven, G.; Bennink, R.J.; Engelbrecht, M.R.; Schoorlemmer, A.; Beuers, U.H.W.; et al. Modern work-up and extended resection in perihilar cholangiocarcinoma: The AMC experience. Langenbeck's Arch. Surg. 2018, 403, 289-307. [CrossRef]

51. Gerhards, M.F.; Van Gulik, T.M.; De Wit, L.T.; Obertop, H.; Gouma, D.J. Evaluation of morbidity and mortality after resection for hilar cholangiocarcinoma-a single center experience. Surgery 2000, 127, 395-404. [CrossRef]

52. Ota, T.; Araida, T.; Yamamoto, M.; Takasaki, K. Operative out-come and problems of right hepatic lobectomy with pancreatoduodenectomy for advanced carcinoma of the biliary tract. J. Hepato-Biliary-Pancreat. Surg. 2000, 14, 155-158. [CrossRef] 
53. Yamanaka, N.; Yasui, C.; Yamanaka, J.; Ando, T.; Kuroda, N.; Maeda, S.; Ito, T.; Okamoto, E. Left hemihepatectomy with microsurgical reconstruction of the right-sided hepatic vasculature: A strategy for preserving hepatic function in patients with proximal bile duct cancer. Langenbeck's Arch. Surg. 2001, 386, 364-368. [CrossRef]

54. Sakamoto, Y.; Sano, T.; Shimada, K.; Kosuge, T.; Kimata, Y.; Sakuraba, M.; Yamamoto, J.; Ojima, H. Clinical significance of reconstruction of the right hepatic artery for biliary malignancy. Langenbeck's Arch. Surg. 2006, 391, 203-208. [CrossRef]

55. Wang, S.-T.; Shen, S.-L.; Peng, B.-G.; Hua, Y.-P.; Chen, B.; Kuang, M.; Li, S.-Q.; He, Q.; Liang, L.-J. Combined vascular resection and analysis of prognostic factors for hilar cholangiocarcinoma. Hepatobiliary Pancreat. Dis. Int. 2015, 14, 626-632. [CrossRef]

56. Matsuyama, R.; Mori, R.; Ota, Y.; Homma, Y.; Kumamoto, T.; Takeda, K.; Morioka, D.; Maegawa, J.; Endo, I. Significance of vascular resection and reconstruction in surgery for hilar cholangiocarcinoma: With special reference to hepatic arterial resection and reconstruction. Ann. Surg. Oncol. 2016, 23, 475-484. [CrossRef] [PubMed]

57. Noji, T.; Tsuchikawa, T.; Okamura, K.; Tanaka, K.; Nakanishi, Y.; Asano, T.; Nakamura, T.; Shichinohe, T.; Hirano, S. Concomitant hepatic artery resection for advanced perihilar cholangiocarcinoma: A case-control study with propensity score matching. J. Hepato-Biliary-Pancreat. Sci. 2016, 23, 442-448. [CrossRef]

58. Peng, C.; Li, C.; Wen, T.; Yan, L.; Li, B. Left hepatectomy combined with hepatic artery resection for hilar cholangiocarcinoma: A retrospective cohort study. Int. J. Surg. 2016, 32, 167-173. [CrossRef]

59. Hu, H.-J.; Jin, Y.-W.; Zhou, R.-X.; Shrestha, A.; Ma, W.-J.; Yang, Q.; Wang, J.-K.; Liu, F.; Cheng, N.-S.; Li, F.-Y. Hepatic artery resection for bismuth type III and IV hilar cholangiocarcinoma: Is reconstruction always required? J. Gastrointest. Surg. 2018, 22, 1204-1212. [CrossRef]

60. Schimizzi, G.V.; Jin, L.X.; Davidson, J.T.; Krasnick, B.A.; Ethun, C.G.; Pawlik, T.M.; Poultsides, G.; Tran, T.; Idrees, K.; Isom, C.A.; et al. Outcomes after vascular resection during curative-intent resection for hilar cholangiocarcinoma: A multi-institution study from the US extrahepatic biliary malignancy consortium. HPB 2018, 20, 332-339. [CrossRef] [PubMed]

61. Kotenko, O.; Popov, A.; Korshak, A.; Fedorov, D.; Grinenko, A.; Gusev, A.; Grigorian, M.; Ostapishen, A. Results of portal vein and hepatic artery resection for surgical treatment of Klatskin tumor. HPB 2019, 21, S892. [CrossRef]

62. Mizuno, T.; Ebata, T.; Yokoyama, Y.; Igami, T.; Yamaguchi, J.; Onoe, S.; Watanabe, N.; Kamei, Y.; Nagino, M. Combined vascular resection for locally advanced perihilar cholangiocarcinoma. Ann. Surg. 2020. [CrossRef]

63. Nagino, M.; Ebata, T.; Yokoyama, Y.; Igami, T.; Mizuno, T.; Yamaguchi, J.; Onoe, S.; Watanabe, N. Hepatopancreatoduodenectomy with simultaneous resection of the portal vein and hepatic artery for locally advanced cholangiocarcinoma: Short- and long-term outcomes of superextended surgery. J. Hepato-Biliary-Pancreat. Sci. 2021, 28, 376-386. [CrossRef] [PubMed]

64. De Santibanñes, E.; Ardiles, V.; Alvarez, F.A.; Pekolj, J.; Brandi, C.; Beskow, A. Hepatic artery reconstruction first for the treatment of hilar cholangiocarcinoma bismuth type IIIB with contralateral arterial invasion: A novel technical strategy. HPB 2012, 14, 67-70. [CrossRef] [PubMed]

65. Iida, T.; Mihara, M.; Narushima, M.; Yoshimatsu, H.; Hara, H.; Koshima, I. Preexcisional artery reconstruction: A new strategy in multiple hepatic artery reconstruction for reducing ischemic injury of the liver. Microsurgery 2012, 32, 493-496. [CrossRef] [PubMed]

66. Uchiyama, H.; Shirabe, K.; Araki, K.; Sugimachi, K.; Morita, K.; Takenaka, K.; Maehara, Y. Left hepatectomy with simultaneous hepatic artery and portal vein reconstructions in the operation for cholangiocarcinoma: The surgical techniques comprised of step-by-step established procedures. Transl. Gastroenterol. Hepatol. 2017, 2, 34. [CrossRef]

67. Savier, E.; Eyraud, D.; Taboury, J.; Vaillant, J.C.; Hannoun, L. Técnicas y modalidades de exclusión vascular del hígado y de las hepatectomías extremas. EMC Técnicas Quirúrgicas-Apar. Dig. 2009, 25, 1-21. [CrossRef]

68. Watson, C.J.E.; Harper, S.J.F. Anatomical variation and its management in transplantation. Am. J. Transplant. 2015, 15, 1459-1471. [CrossRef]

69. Govil, S.; Bharatan, A.; Rammohan, A.; Kanagavelu, R.; Kaliamoorthy, I.; Reddy, M.S.; Rela, M. Liver resection for perihilar cholangiocarcinoma-why left is sometimes right. HPB 2016, 18, 575-579. [CrossRef]

70. Torres, O.J.M.; Alikhanov, R.; Li, J.; Serrablo, A.; Chan, A.C.; Fernandes, E.D.S.M. Extended liver surgery for gallbladder cancer revisited: Is there a role for hepatopancreatoduodenectomy? Int. J. Surg. 2020, 82, 82-86. [CrossRef]

71. D’Souza, M.A.; Valdimarsson, V.T.; Campagnaro, T.; Cauchy, F.; Chatzizacharias, N.A.; D’Hondt, M.; Dasari, B.; Ferrero, A.; Franken, L.C.; Fusai, G.; et al. Hepatopancreatoduodenectomy-a controversial treatment for bile duct and gallbladder cancer from a European perspective. HPB 2020, 22, 1339-1348. [CrossRef]

72. Bhangui, P.; Salloum, C.; Lim, C.; Andreani, P.; Ariche, A.; Adam, R.; Castaing, D.; Kerba, T.; Azoulay, D. Portal vein arterialization: A salvage procedure for a totally de-arterialized liver. The Paul Brousse hospital experience. HPB 2014, 16, 723-738. [CrossRef] [PubMed]

73. Tan, E.K.; Taner, T.; Heimbach, J.K.; Gores, G.J.; Rosen, C.B. Liver transplantation for peri-hilar cholangiocarcinoma. J. Gastrointest. Surg. 2020, 24, 2679-2685. [CrossRef] [PubMed]

74. Loveday, B.P.; Knox, J.J.; Dawson, L.; Metser, U.; Brade, A.; Horgan, A.M.; Gallinger, S.; Greig, P.D.; Moulton, C.-A. Neoadjuvant hyperfractionated chemoradiation and liver transplantation for unresectable perihilar cholangiocarcinoma in Canada. J. Surg. Oncol. 2018, 117, 213-219. [CrossRef] [PubMed] 
75. Mantel, H.T.J.; Westerkamp, A.C.; Adam, R.; Bennet, W.F.; Seehofer, D.; Settmacher, U.; Sánchez-Bueno, F.; Prous, J.F.; Boleslawski, E.; Friman, S.; et al. Strict selection alone of patients undergoing liver transplantation for hilar cholangiocarcinoma is associated with improved survival. PLOS ONE 2016, 11, e0156127. [CrossRef]

76. Ethun, C.; Lopez-Aguiar, A.; Anderson, D.; Adams, A.; Fields, R.; Doyle, M.; Chapman, W.; Krasnick, B.; Weber, S.; Mezrich, J.; et al. Transplantation versus resection for hilar cholangiocarcinoma: An argument for shifting treatment paradigms for resectable disease. HPB 2017, 19, S1-S2. [CrossRef] 